PREFACE

\title{
Facial Paralysis
}

There is nothing more challenging in peripheral nerve surgery than reanimation of the paralyzed face. The neural topography is complex, and aberrant regeneration is often complicated with synkinesis. Facial muscles are small, numerous, and impossible to replace, even with the most carefully designed free muscle transfers. The nuances of facial expression and the uniqueness of the human smile can never be restored with surgical reconstruction. Most important, the psychological and emotional impact of facial nerve palsy can be devastating and only truly appreciated by the individual affected. This Seminars in Plastic Surgery presents an overview of the management of the paralyzed face with contributions from several different specialties. From otolaryngology, Drs. Brenner and Neely discuss the grading systems currently utilized for measuring facial nerve function. From ophthalmology, Dr. Custer discusses reanimation of the paralyzed eye. Ms. Novak, PT, reviews rehabilitation of the paralyzed face. Dr. Myckatyn, a plastic surgeon, discusses the complicated anatomy of the facial nerve. Drs. Manktelow, Singham, and Zuker review the challenging problem of reinnervation of patients with bilateral facial palsies. Drs. Rovak and Tung discuss free muscle transfer and temporalis transfer for reanimation of the paralyzed face. Finally, Drs. Klebuc and Shenaq discuss the nuances of gracilis muscle transfer.

I am very appreciative of the time and effort that these authors have spent preparing these articles, which will provide important information for the readership and translate into a better surgical outcome for patients afflicted with this devastating nerve palsy.

Susan E. Mackinnon, M.D., F.R.C.S. Guest Editor ${ }^{1}$

Facial Paralysis; Editor in Chief, Saleh M. Shenaq, M.D.; Guest Editor, Susan E. Mackinnon, M.D. Seminars in Plastic Surgery, Volume 18, Number 1, 2004. Address for correspondence and reprint requests: Susan E. Mackinnon, M.D., Suite 17424, East Pavilion, 1 Barnes-Jewish Hospital Plaza, St. Louis, MO 63110. E-mail: mackinnons@msnotes.wustl.edu. ${ }^{1}$ Division of Plastic Surgery, Washington University School of Medicine, St. Louis, MO. Copyright (C) 2004 by Thieme Medical Publishers, Inc., 333 Seventh Avenue, New York, NY 10001 USA. Tel: +1(212) 584-4662. 1535-2188,p;2004,18,01,003,004,ftx,en;sps00102x. 
